\title{
UN BUEN MEDIO PARA UN BUEN FIN: UNA VISIÓN UTILITARISTA DE LA DEMOCRACIA ${ }^{1}$
}

\author{
BLANCA RODRÍGuez LóPEZ \\ Universidad Compultense de Madrid
}

\begin{abstract}
RESUMEN
La conexión entre utilitarismo y democracia siempre ha sido estrecha, hasta el punto de que algunos autores consideran que la democracia no es sino el utilitarismo aplicado a la política. Este punto de vista es discutible, pero sin duda los principales utilitaristas han sido defensores de la democracia, si bien sus propuestas prácticas han sido distintas, así como también lo han sido los argumentos presentados para su defensa. En este trabajo analizamos las principales causas de esas variaciones: las diferencias existentes en las propias propuestas utilitaristas de los distintos autores y la diversidad de las circunstancias históricas y políticas en que las mismas se presentaron.
\end{abstract}

Palabras clave: Utilitarismo, democracia, representación Bentham, Mill, Singer.

\begin{abstract}
Utilitarianism and democracy had always been related, to the point that for same authors democracy is nothing but political utilitarianism. Though his claim can be challenged, utilitarians had always supported democracy. However, their main arguments and proposals had been remarkably different. In this paper we analyze these differences in terms both of the intrinsic differences in their theoretical proposals and of the changing historical and political context.
\end{abstract}

Keywords: Utilitarianism, democracy, representation, Bentham, Mill, Singer.

Democracia es una palabra de origen griego, acuñada por los atenienses para referirse a su propia forma de gobierno. Etimológicamente, significa gobierno "del pueblo"o "popular". Dejando aparte le etimología, su

1 Recepción: 31 de agosto de 2010. Aceptación: 20 de diciembre de 2010.

Este trabajo se ha gestado en el marco de un proyecto del MICINN, referencia FFI200806414-C03-01 y de una Acción Complementaria FFI2010-09501-E (subprograma FILO).

Té̀os, Vol. XVII/2, 2010 (189-208) 
significado no se ha mantenido estable. Formas de gobierno absolutamente distintas se han calificado a sí mismas de democracia. Sin embargo, en nuestros días hay cierto acuerdo en torno a una definición de democracia que debemos a Abraham Lincoln: es un gobierno del pueblo, por el pueblo y para el pueblo. Pero ni siquiera esto elimina la discusión en torno al significado de la democracia pues, como mínimo, tendríamos que precisar lo que entendemos por "pueblo", y también cuándo podemos decir que el poder reside en el sujeto de ese modo precisado. En nuestro contexto, hay una dificultad añadida. "Democracia" ha adquirido un significado valorativo que se superpone a su significado descriptivo hasta el punto de oscurecerlo. Sin embargo, una mirada a la historia nos enseña que la democracia ha tenido, sobre todo, aunque no únicamente, entre los intelectuales, más detractores que defensores. ${ }^{2}$ Ha tenido amigos y enemigos. En este trabajo hablaremos sólo de los primeros, y en especial de los utilitaristas. El motivo es sencillo: los utilitaristas siempre han defendido la democracia, hasta el punto de que algunos autores consideran que la democracia no es sino el utilitarismo aplicado a la política.

\section{Democracia RePresentativa: Un gobierno del PUeblo Para El PUEblo}

El modelo griego de democracia corresponde a lo que en la actualidad llamamos democracia directa. El pueblo tiene la soberanía y la ejerce de modo directo. Este modo de gobierno dependía de una forma de vida, la de la polis, que desapareció al desaparecer esta. Dependía no solo de un número relativamente pequeño de ciudadanos, sino también de la existencia de un número no pequeño de no ciudadanos (mujeres, esclavos, metecos) en los que recaía en buena medida la actividad económica. Si insistimos en que democracia es el nombre que los atenienses inventaron para designar su propio sistema, no ha vuelto a haber (casi nunca) democracia en el mundo. Pero las palabras cambian de significado y se adaptan para designar realidades nuevas. Sin embargo, para que se pueda hablar de evolución del significado y no de cambio, hay un núcleo significativo que debe permanecer constante. En nuestro caso, el núcleo significativo se refiere a la titularidad de la soberanía. Cuando la cuestión es ¿quién tiene la titularidad de la soberanía? una posible respuesta es "el pueblo", y a esta respuesta llamamos democracia.

Desde el siglo XIX, el concepto de democracia se ha impuesto referido a las relaciones entre estado y sociedad. Se define como una forma de

2 Solo tenemos que pensar en la oposición frontal de Platón y en la defensa matizada de Aristóteles, por no mencionar a Hobbes, ya en la edad moderna. 
gobierno en que el poder político del Estado, la soberanía, pertenece por derecho a todo el pueblo, entendido como el conjunto (casi) universal de ciudadanos, sin exclusiones por razones de sexo o clase social, y no a un grupo específico y limitado del mismo.

Por lo general, los filósofos están de acuerdo en que el gobierno debe ejercerse en beneficio del pueblo, aun cuando discrepan cuando intentan determinar en qué consiste este. Sin embargo, tal cosa no supone una defensa de la democracia. Gobernar en beneficio del pueblo es algo que pueden hacer otras formas de gobierno. La mayoría de los enemigos de la democracia creen, en realidad, que esta no es un buen medio para promover este fin. De hecho, en algunos momentos fue habitual la defensa de un despotismo ilustrado ${ }^{3}$. Todo para el pueblo pero sin el pueblo.

Los que defienden que el gobierno debe ser no solo para el pueblo, sino también ejercido por este, es decir, los demócratas que suscriben la teoría de la soberanía popular, pueden también discrepar entre sí. ¿Cómo ejerce la soberanía el titular de la misma? ¿Cómo debe concebirse esa entidad a la que llamamos "pueblo"? Y puesto que soberanía es, en la definición clásica de Bodino, el poder supremo de una república, ¿Cómo se distribuye entre el pueblo ese poder? ¿Qué límites tiene, si es que tiene alguno? ¿Cómo se deciden los asuntos públicos? En la actualidad, casi todos los defensores de la democracia contestan estas preguntas con una misma respuesta: el pueblo no es sino el conjunto de los individuos, la soberanía la ejercen sus representantes electos, el poder se distribuye de manera igualitaria y universal (entre todos los mayores de edad), es decir, las elecciones de los representantes y otras decisiones se realizan por sufragio universal, y el voto de todos los individuos tiene el mismo valor, es un poder limitado (es una democracia liberal) y la regla de decisión es el voto de la mayoría. Pero ni siempre ha sido así ni tiene por que serlo. Las respuestas que por ser habituales han adquirido el carácter de lo evidente distan en realidad de serlo y no deben darse por sentadas.

En este trabajo, nos centraremos en la primera parte de la definición de Lincoln (un gobierno del pueblo), tal y como ha sido concebida por los utilitaristas en distintas épocas.

\section{LOS UTILITARISTAS Y LA DEMOCRACIA}

Antes de acometer el objetivo central del presente trabajo, es útil echar una mirada, por rápida que sea, a la segunda parte de la definición, tal y como es interpretada por los utilitaristas.

3 Por ejemplo, para Voltaire lo mejor es una dictadura benevolente en la cual un déspota ilustrado gobierna en interés del pueblo pero sin consultarle. También Bentham, en su primera etapa, miraba con simpatía la posibilidad de una dictadura ilustrada. 


\section{Para el pueblo}

La pregunta por la legitimidad de un gobierno, y por consiguiente por la obligación de obedecerlo, es una de las más antiguas dentro de la filosofía política. Los autores que conocemos como "contractualistas clásicos" (y no solo ellos) había propuesto la llamada "legitimidad de origen", que fue atacada por Hume ${ }^{4}$. Al expandir el argumento de Hume, Bentham consigue añadir a la crítica negativa un fundamento positivo alternativo. Para fundamentar la legitimidad de la autoridad (y poder discriminar entre una autoridad legítima a la que se debe obediencia y una ilegítima respecto a la que no tenemos tal deber) es necesario acudir a otro principio al margen del origen (supuestamente contractual) de la autoridad y "ese otro principio al que tenemos que acudir, ¿puede ser algún otro que el principio de la utilidad?"5 Es únicamente este principio el que nos proporciona un fundamento que no necesita de otro anterior para sustentarse y que es, por sí solo y en sí mismo, fundamento suficiente para cualquier cuestión práctica.

Bentham, al igual que Hobbes y Hume, parte de un análisis de la naturaleza humana, a la que concibe en términos similares al primero, influenciado por Helvetius, un filósofo francés cuya principal obra, Del espíritu, había sido publicada en 1758. Para Helvetius, la motivación humana fundamental es el amor a uno mismo, que él identificaba con la búsqueda del placer y la aversión al dolor. Al igual que en Hobbes, este egoísmo no significa que el hombre sea malo, sino simplemente que está sometido a sus propios intereses. Para Helvetius esto no sólo es un hecho, sino un hecho contra el que no se puede luchar. El problema es que, dejados a sus propios impulsos, estos imposibilitarían la propia existencia de la sociedad.

A la vista de esto, la labor del gobierno debe ser la de conseguir que la conducta, necesariamente egoísta, de los humanos, sea compatible con la felicidad general, cosa que puede lograrse siempre y cuando no se pierda de vista que lo único que puede mover a los hombres es su propio interés. Los hombres tienen sus propios intereses y con frecuencia, estos entran en conflicto. La tarea fundamental de los gobiernos consiste en armonizar estos intereses potencialmente conflictivos. Para Bentham, esta armonía

Hume plantea la cuestión en diversos ensayos, por ejemplo en "Del origen del gobierno" y "Del contrato original". Ambos pueden encontrarse en Hume (1987).

5 "By the principle of utility is meant that principle which approves or disapproves of every action whatsoever, according to the tendency it appears to have to augment or diminish the happiness of the party whose interest is in question: or, what is the same thing in other words to promote or to oppose that happiness" (Bentham 1789, p. 2). Bentham intenta mostrar que este nuevo principio cumple su función mejor que el anterior: da razón de la obligación de obedecer, no recurre a ficciones, y puede mostrarse que el principio anterior puede explicarse mediante el nuevo. 
tiene como objeto maximizar los intereses de la comunidad, entendiendo esta en términos absolutamente individualistas. El interés de la comunidad es la suma de los intereses de sus distintos miembros. Este objetivo puede parecer vago e impreciso, pero Bentham lo concreta en cuatro tareas fundamentales, ordenadas jerárquicamente: proveer la subsistencia, promover la abundancia (a mayor escasez, mayor conflicto de intereses), garantizar la seguridad y promover la igualdad. En la medida en que un gobierno ejerza su autoridad para alcanzar estos objetivos, su autoridad será legítima.

Bentham, por tanto, creía que lo que hacía legítimo a un gobierno era el modo en que este ejercía el poder (legitimidad de ejercicio) y que su tarea era armonizar los intereses conflictivos de los distintos individuos maximizando la utilidad general (consiguiendo, según su máxima, la mayor felicidad para el mayor número). Cualquier tipo de gobierno que alcance este objetivo obtiene el beneplácito del utilitarismo. Por esto, en principio el utilitarismo no supone la defensa de un tipo determinado de gobierno. De hecho, es habitual mencionar que el propio Bentham, en lo que suele clasificarse como una primera etapa de su obra, creía en la posibilidad de alcanzar este objetivo mediante un despotismo ilustrado.

Sin embargo, en la filosofía de Bentham se encuentran algunas características que, al desarrollarse, conducen de manera natural a una defensa de la democracia, defensa que él mismo realizó, si se acepta esa división de su obra, en su segunda etapa. En particular, hay en Bentham:

- Una visión antropológica, según la cual los individuos tienen intereses y buscan la promoción de los mismos (están motivados por la busca de su felicidad), que conocemos como supuesto de la autopreferencia y tienen además una capacidad racional suficiente para juzgar tanto sus propios intereses como los medios adecuados para conseguirlos.

- Un concepto de la sociedad. La sociedad no tiene intereses distintos de los de los individuos: el interés de la comunidad es la suma de los intereses de los individuos.

- Un supuesto ético igualitario: la felicidad de todos los individuos tiene el mismo valor.

- Una cuestión de hecho. Siempre existen conflictos de intereses. Por tanto es necesaria una armonización artificial de los mismos. La política es el arte de armonizar los intereses de los distintos individuos de una sociedad. 


\section{LA DEMOCRACIA COMO MEDIO}

Estas ideas estaban ya en Hobbes, y no implican por sí mismas una defensa de la democracia. El argumento a favor de la democracia parte de la aplicación de la visión antropológica y el supuesto de la autopreferencia a los gobernantes. Por eso el poder no debe estar en manos de un monarca ni de una minoría, los órganos de gobierno deben ser representativos y elegidos por sufragio universal (el único posible, dado su supuesto ético igualitario), y el poder debe estar sometido y subordinado al control público ${ }^{6}$.

Los estudiosos de Bentham suelen mencionar varios motivos que explican que se convirtiera en un ferviente defensor de la democracia, y entre ellos está su relación con James Mill, con el que entró en contacto en 1808. Aunque de temperamentos y procedencias completamente distintos, ambos hombres compartían intereses, inquietudes y puntos de vista. En especial compartían su interés por reformar tanto el sistema legal como el sistema político inglés. La revolución Gloriosa había establecido en 1688 una monarquía constitucional con un parlamento bicameral, pero el sistema resultante tenía problemas que se agravaron con los años y estaba lejos de ser una democracia ${ }^{7}$. Bentahm había defendido el sufragio universal antes de conocer a James Mill (de hecho, antes de la Revolución francesa, lo que le valió que, tras la Revolución, la asamblea nacional francesa le nombrara ciudadano de honor) pero sin duda la asociación de los dos hombres reforzó sus ideas: definitivamente, no era posible que aristócratas y

6 En una obra publicada en 1817 Plan para la reforma parlamentaria, defiende la democracia representativa argumentando que el único modo de reconciliar la autopreferencia de los gobernantes con la promoción del interés general es hacer que los gobernantes democráticamente elegidos sean responsables ante sus electores, pues de este modo sus intereses coincidirán con los de estos.

7 A finales del siglo XVIII el monarca tenía aún una considerable influencia sobre el Parlamento y este estaba además dominado por la aristocracia. Los candidatos a la Casa de los Comunes se presentaban, ciertamente, como Whigs o como Tories, pero una vez elegidos establecían coaliciones que defendían unos intereses más o menos particulares. El sufragio era censitario y estaba restringido a los propietarios. Además respondía a circunscripciones completamente desfasadas. No habían cambiado desde 1660 y no es de sorprender que, en siglo y medio, ciudades que eran importantes hubieran dejado de serlo y otras, prácticamente inexistentes a mediados del XVII, hubieran cobrado esplendor y población. La situación cobraba en ocasiones tintes absurdos en algunos distritos municipales. Por ejemplo, había un caso (Old Sarum) en el que el número de votantes era seis y tenían derecho a dos diputados. No es de extrañar que estos distritos fueran conocidos con el expresivo nombre de "distritos podridos" (rotten boroughs). $\mathrm{Al}$ mismo tiempo, ciudades como Manchester carecían de representación propia. En otros distritos, también con poco electorado, los aristócratas y grandes propietarios se las arreglaban sistemáticamente para "colocar" a sus candidatos. Ante esta situación, es comprensible que Bentham y James Mill unieran fuerzas con objeto de cambiar el sistema de circunscripciones obsoleto, eliminando los "distritos podridos",y de extender el sufragio 
reyes dejaran de lado sus intereses y defendieran los de la sociedad. Como suele suceder, la unión de dos hombres tan distintos dio sus frutos y las ideas utilitaristas empezaron a extenderse, formando un grupo heterogéneo pero muy activo ${ }^{8}$.

Bentham procuró a James Mill apoyo financiero (James era pobre y provenía de una familia realmente modesta). James Mill, con su estilo claro y conciso (seco y nada atractivo, según sus críticos) hizo digerible la doctrina de Bentham, facilitando así su difusión. Esta labor se concretó, en especial, en su Ensayo sobre el gobierno publicado en 1820. En esta obra James ponía en claro la visión utilitarista acerca del gobierno y defendía que su objetivo no podía ser alcanzado ni por una monarquía ni por una aristocracia. Argumentaba también en contra de la democracia directa. En un sistema así, la dedicación casi a tiempo completo requerida por la labor política sustraería esfuerzos a la labor productiva, lo que haría disminuir gravemente el bienestar de la humanidad. La mejor alternativa era sin duda la democracia representativa, el "gran descubrimiento de los tiempos modernos". En este sistema, los ciudadanos elegían representantes para que legislaran defendiendo sus intereses. Naturalmente, el supuesto de la autopreferencia de los gobernantes hace que sea necesario arbitrar medios que les obliguen a defender los intereses de los votantes y no los propios. La solución está en realizar elecciones frecuentes y establecer mandatos cortos. De este modo, los ex gobernantes volverían a formar parte de los ciudadanos de a pie y tendrían que sufrir las consecuencias de las leyes que habían aprobado. El sistema facilitaría la identificación de los intereses de los gobernados con los de los gobernantes. Además defendía que el interés público sólo podía estar representado si se extendía el derecho al voto. James Mill era un individualista radical e insistía en que cada uno es el mejor juez de sus propios intereses y por tanto debe expresarlos mediante el voto. Solo la extensión del sufragio podía hacer que el gobierno fuera verdaderamente representativo. El sufragio debía ser por tanto universal, e incluir a las mujeres.

\section{John Stuart Mill y la Democracia}

Aunque Mill fue crítico con el utilitarismo, heredado de su padre y de Bentham, coincidía plenamente con ellos en que la democracia es la mejor

8 Este círculo utilitarista se articuló en torno a la Sociedad para la difusión del conocimiento útil (Society for the Diffusion of Useful Knowledge) y fundó en 1823 la Westminster Review, una revista trimestral que se publico hasta 1914, que articulaba y daba voz a los que se denominaron a sí mismos "radicales filosóficos" (philosophical radicals) que trabajaron incansablemente y con entusiasmo a favor de los cambios políticos mencionados, muchos de los cuales fueron incorporados en la reforma de 1832. 
forma de gobierno. Su defensa se encuentra recogida fundamentalmente en Del gobierno representativo, publicada en 1861, y de la que celebramos hace poco el 150 aniversario. El objeto de esta obra no es otro que el de determinar cuál es la mejor forma de gobierno.

Para saber cuál entre varios relojeros es el mejor tenemos que tener un criterio y el criterio hay que extraerlo de su función. Puesto que un relojero hace y repara relojes, habrá que fijarse en cómo realiza esta tarea. Siguiendo este procedimiento Mill empieza por preguntarse cuál es la función de un gobierno porque "siendo el gobierno pura y simplemente un medio, su elección debe depender de la manera como se adapte al fin deseado". Siguiendo la línea utilitarista, este fin deseado es el bienestar de los gobernados, el bienestar de la sociedad sobre la que el gobierno ejerce su poder. A su vez, el bienestar de la sociedad dependerá de la conservación de los bienes (de todo tipo, no solo estrictamente materiales) que ya existen y de su aumento. Esto es por tanto lo que debe hacer un gobierno y el criterio por el que hay que juzgarlo. De esta forma, Mill expresa la vieja doctrina utilitarista de la legitimidad de ejercicio y la finalidad del gobierno. La parte más original de su teoría aparece cuando utiliza este criterio para encontrar el gobierno ideal.

La principal materia prima de la que se obtiene un buen gobierno está compuesta de seres humanos. De nada sirve, por ejemplo, un sistema de justicia que formalmente ofrezca todas las garantías posibles si luego los testigos mienten y los magistrados se dejan sobornar. No hay sistema que resista la corrupción generalizada. Así que "dondequiera que la disposición general del pueblo sea tal que cada individuo atienda únicamente a sus intereses personales y no se cuide o abandone los generales, es imposible un buen gobierno". Cualquiera de sus antecesores hubiera podido firmar esta frase. En efecto, dirían, y para eso sirve la democracia, para asegurar que los individuos se cuidan de sus propios intereses (cosa inevitable) y al mismo tiempo de los generales, haciendo que estos coincidan. Pero Mill no parece confiar en que el puro diseño institucional fuera capaz de obrar el milagro, sino que requiere también "la virtud y la inteligencia de las personas que componen la comunidad", aunque no por ello desprecia el mecanismo institucional y afirma que "siempre es preferible un aparato bueno a uno malo". Por mucho que uno bueno en manos incompetentes sea ineficaz, tampoco es posible hacer funcionar uno malo por mucha competencia que tenga el operario. El requisito de la inteligencia es poco discutible: los individuos pueden querer alcanzar un objetivo, pero si no saben cómo hacerlo no se adelanta mucho. Si esta falta de inteligencia es pronunciada, la democracia podría incluso empeorar las cosas pues los votantes podrían forzar a sus representantes (bajo amenaza de no volverlos a elegir, por 
ejemplo) a tomar decisiones que conducen al desastre. La cuestión de la virtud es menos clara y a decir verdad Mill no arroja mucha luz al respecto. Casi todos los ejemplos que ofrece están relacionados con la inteligencia y no con la virtud. Parece referirse, simplemente a que los individuos no deberían decidir en cuestiones políticas pensando en su interés particular sino en el general. En cualquier caso, enfocar las características individuales le sirve a Mill para ofrecer una defensa de la democracia peculiar y con cierto aire paradójico: un buen gobierno sólo es posible si los individuos tienen ciertas cualidades y el buen gobierno es el que puede desarrollarlas.

Mill afirma que la forma ideal de gobierno es la que consigue dos cosas: aprovechar las cualidades existentes en un momento determinado para cuidarse lo mejor posible del interés general y mejorar estas cualidades. $\mathrm{Y}$ esta forma ideal es "el gobierno completamente popular". Del primer objetivo extrae dos de los argumentos con los que defiende la democracia. El primero aparecía ya en sus antecesores: "los derechos e intereses, de cualquier clase que sean únicamente no corren el riesgo de ser descuidados cuando las personas a que atañen se encargan de su dirección y defensa". El segundo está relacionado con su valoración de la discusión y la confrontación de las opiniones que, en una obra publicada dos años antes, Sobre la libertad, había desarrollado por extenso para defender la libertad de prensa y la libertad de opinión en general. El argumento se resume en que "la prosperidad general se eleva y difunde tanto más cuanto más variadas e intensas son las facultades consagradas a su desenvolvimiento". Cuatro ojos siempre ven más que dos, y más aún si son ojos sanos y agudos.

El tercer argumento está relacionado con el segundo objetivo. Cuando la gente se cuida de sus propios asuntos y la buena marcha de estos depende de ellos, desarrollan una serie de cualidades, un "carácter activo" que no sólo es beneficioso para la marcha de los asuntos públicos sino también de sus asuntos privados. Se tomarán mayor interés, desarrollarán una mayor capacidad reflexiva, su pensamiento será más racional, se acostumbraran a defender con argumentos sus posiciones y a escuchar los argumentos de los demás, ejercitarán la simpatía al estar obligados a ver las cosas desde el punto de vista de los demás etc. Desarrollarán su autonomía. Y este es para Mill el argumento decisivo. Los otros dos podrían servir para apoyar un déspota ilustrado. Sería, desde luego, difícil de encontrar pues "hace falta un monarca que no sólo sea bueno, sino que sea capaz de verlo y examinarlo todo". Pero aunque lo encontráramos lo que tendríamos sería "un hombre e actividad sobrehumana dirigiendo todos los asuntos de un pueblo intelectualmente pasivo".

¿Es convincente este argumento? Desde luego, no hay problema en admitir que un gobierno despótico ideal (y por lo demás irreal) podría tomar 
en cuenta los intereses de todos y suplir con su sola inteligencia las inteligencias conjuntadas de los ciudadanos pero que no podría hacer que estos fueran mejores. Pero esto no demuestra nada. Si queremos elevar y mejorar las cualidades de los ciudadanos es para conseguir mejor el bienestar común. Si el déspota puede hacer esto, entonces ¿para que queremos mejorar a los ciudadanos? El argumento de Mill se parece al que muchos padres, preocupados por el bienestar de sus hijos, utilizan para explicarles porqué tienen que aprender a hacer la cama o la comida, porqué tienen que aprender a buscar por sí mismos las palabras en el diccionario o interpretar por sí mismos un texto, porqué tienen que aprender a solucionar ellos solos sus problemas con sus amigos y, en general, porqué tienen que aprender a desenvolverse solos. Valerse por sí mismos y solucionar sus propios asuntos. Claro, que tu puedes hacerlo por ellos. Entonces, ¿por qué tienen que aprender? Una respuesta habitual es "por qué yo no voy a estar siempre aquí para solucionar tus asuntos". Esto, desde luego, es verdad y es sin duda una muy buena razón. Pero si esto es todo lo que tenemos que decir, entonces una madre eterna, benevolente y sabia, o una sucesión de tutores benevolentes y sabios harían innecesario que el niño, por su propio bien, aprendiera a ocuparse de sus propios asuntos.

Transportado al caso del déspota y el bienestar de los ciudadanos, si esta es toda la razón, un déspota eterno o una sucesión de déspotas solucionarían el asunto. Desde luego, si ya suponer la existencia de este déspota es irreal, pedir además que sea inmortal o que haya todo un linaje que se suceda en el puesto alcanza los límites más extremos de la ficción. Sin embargo, no es esa la razón de fondo que Mill ofrece. Hay otra mucho más importante que muestra que el déspota (o el linaje de déspotas) no puede funcionar por motivos que no tienen nada que ver con la dificultad o incluso imposibilidad de su existencia. Lo que Mill quiere decirnos es que aunque existiera y no fueran a irse nunca, aunque sucediera lo imposible, aún tendríamos razones para despreciarlos. Hay un objetivo que el déspota no puede alcanzar y se trata de una imposibilidad lógica. Podemos ver esto en el caso de los padres y los niños.

Hay otra cosa que una madre puede decir para explicar porque debe su hijo aprender a ser independiente, razón que seguiría vigente aunque ella fuera inmortal. Ser independiente es importante, no sólo (aunque también) porque esto pueda procurarte determinadas cosas. Ser independiente es valioso en sí mismo. Es lo mejor y más importante que un ser humano puede ser llegar a ser. Ser independiente, libre, desarrollar la individualidad y, en definitiva, la autonomía, es lo que hace posible que seamos seres humanos plenamente desarrollados, con nuestras propias capacidades (sean las que sean) desarrolladas al máximo. Esta es exactamente la opinión de Mill. 
Procurar el desarrollo de las capacidades de los individuos no sólo es bueno (aunque sin duda también lo es) para poder de este modo alcanzar mejor el bienestar general. Es que también es bueno, Mill diría imprescindible, para la propia felicidad privada de los individuos. Para Mill, no hay felicidad sin autonomía, sin individualidad y sin libertad. Y esto es lo que un déspota no puede hacer. Un déspota tiene subordinados. Los subordinados pueden estar bien alimentados, tener más que satisfechas sus necesidades, colmados todos sus deseos. Pero mientras sigan siendo subordinados, sin autonomía, sin libertad, no alcanzarán la autentica felicidad propia de los humanos. Para alcanzarla, tienen que ser responsables de su propia vida, ocuparse de sus propios asuntos. Librarse del déspota y de la servidumbre.

Por supuesto, todo esto no se sostiene a menos que Mill sea capaz de argumentar de forma convincente acerca del puesto que le atribuye a la libertad y la autonomía y su relación con la felicidad. Este es uno de los objetivos de su obra sobre la libertad y su examen sobrepasa los límites de este trabajo. Ahora tenemos que ocuparnos de otras cuestiones relacionadas con su defensa de la democracia.

\section{¿DEMOCRACIA REPRESENTATIVA?}

Algunas de las razones de Mill para defender la democracia (aquellas que comparte con los utilitaristas anteriores) pueden utilizarse en defensa de la democracia representativa. Sin embargo su argumento más original, el que se refiere a la potenciación de las cualidades intelectuales y morales de los individuos ,no solo puede utilizarse también en defensa de la democracia directa, sino que parece que solo puede referirse a esta. Solo hay que pensar en el sistema de gobierno bajo el que vivimos actualmente. ¿De verdad puede alguien sostener que votar una vez cada cuatro años (bueno, con mayor frecuencia si contamos autonómicas, municipales y europeas, digamos cada dos) mejora nuestras capacidades? Incluso si incluimos la atención prestada al examen concienzudo de los programas electorales, asistir a mítines y escuchar a los candidatos (cosa que la mayoría de la gente no hace y que desde luego no es requisito para votar), ¿puede alguien defender en serio que esto nos hace intelectual o moralmente mejores? Mill creía que la democracia directa no es posible en nuestra sociedad, puesto que "en toda comunidad que exceda los límites de una pequeña población nadie puede participar personalmente sino de una porción muy pequeña de los asuntos público el tipo ideal de un Gobierno perfecto es el gobierno representativo". Parece que Mill defiende la democracia representativa simplemente porque la directa es impracticable. Esta impresión es errónea. 
Mill creía que la democracia representativa tenía sus propias ventajas. Antes de ver cuales son conviene precisar que Mill no consideraría (y probablemente nadie lo hace) que ir a votar cada dos (o tres o cuatro años) sea el modelo ideal de una democracia representativa. El nivel de participación de los ciudadanos en una democracia representativa puede variar mucho según los casos, así como la medida en la que los ciudadanos realmente contribuyen a fijar la agenda de sus representantes. Mill creía que participar en los asuntos públicos mejoraba a los individuos y podemos suponer que esa mejora depende crucialmente de hasta qué punto participen. Por ejemplo, siguiendo en esto como en otras cosas a Tocqueville, Mill señala la importancia de la participación en los gobiernos locales o en los jurados.

La democracia es una forma de gobierno particularmente exigente. La democracia directa tiene una exigencia máxima que hace que la política ocupe casi todo el espacio de la vida del ciudadano. Esta es una de las razones por las que James Mill favorecía la forma representativa, pues libera espacio para el individuo privado, para sus negocios e intereses particulares. Pero incluso la forma representativa tiene unas exigencias no pequeñas. Al comienzo de este apartado hacíamos dos preguntas. La respuesta a la primera (si votar cada cuatro años potenciaba el desarrollo de nuestras capacidades) es evidentemente negativa. La segunda es una pregunta malvada. Podemos tener la tentación de responderla también negativamente, pero esto requiere mayores matices. Democracia no es ir a votar. Pero sí es informarnos para tomar una decisión adecuada, estudiar y considerar las propuestas del los partidos, sus programas, escuchar los debates entre los candidatos, prestar atención a las tertulias políticas etc., y estar dispuestos, fuera del periodo electoral, a pedir cuentas, a seguir la acción del gobierno etc. Y esto no es algo que se haga en quince minutos un domingo por la mañana antes del aperitivo. Si la gran mayoría de un pueblo no hace nada de esto, incluso aunque vaya a votar, las bondades del gobierno representativo desaparecen.

Las ventajas de la democracia representativa, por otra parte, están relacionadas con algunas de las críticas que pueden hacerse a la democracia directa. Mill confía en que la democracia representativa haga posible que el gobierno esté en manos de los mejores, pues los individuos elegirán a los más capacitados y dejarán que estos disfruten de cierto nivel de autonomía en sus decisiones.

\section{DE LAS ENFERMEDADES Y PELIGROS}

No hay duda de que en 1861, cuando aparece Del gobierno representativo, Mill es un firme defensor de la democracia representativa. Pero esta 
obra es mucho más que esto: es una reflexión profunda sobre sus problemas y una propuesta de los medios que podían ponerse para remediarlos. Si Bentham acabo siendo un demócrata, Mill empezó siéndolo y, después cuestiono y matizó su primitivo, y heredado, entusiasmo democrático. Tras su famosa crisis de 1826 (sin duda la crisis nerviosa más famosa de la historia de la filosofía) cuestionó muchas de las posturas de sus antecesores radicales. Algunos artículos en el Examiner, sus dos recensiones sobre la obra de Tocqueville y su ensayo sobre Coleridge muestran este alejamiento, que según algunos estudiosos alcanzo su punto culminante en 1849 (Burns 1968).

Uno de los mayores riesgos que presentaba la democracia era el de, en expresión por él popularizada, la tiranía de la mayoría. Fue Tocqueville quien primero lo advirtió, y abordó en su obra La democracia en América un problema radicalmente nuevo. En los siglos anteriores, las ideas de libertad e igualdad habían ido de la mano. Para los contractualistas, ambas eran características del estado de Naturaleza y para los utilitaristas ambas se defendían en un régimen democrático. En el siglo XIX, derrumbadas en gran medida las estructuras y privilegios del antiguo régimen y establecidos gobiernos democráticos en muchos países del viejo continente y en Estados Unidos, Tocqueville se preguntaba si la amistad entre libertad e igualdad era tan íntima y auténtica como parecía. La democracia política garantizaba la igualdad política de los ciudadanos y la "democracia social" que se apreciaba en Estados Unidos igualaba las condiciones sociales. Esta situación originaba un nuevo poder y los liberales empezaron a preguntarse si este, como todos los poderes, no debería limitarse. Una vez que había triunfado la idea (y hasta cierto punto la práctica) de la soberanía popular, era hora de plantearse si esta soberanía no era tan peligrosa (o más: se puede luchar contra la tiranía de un rey, pero la tiranía de un pueblo es mucho más difícil de resistir) que cualquier otra si no se la sometía a un control. Y en una democracia, la soberanía que hay que limitar es la del pueblo. En On liberty Mill recoge el problema y en esta obra, que es una de las más bellas defensas de la libertad jamás escrita, propone un remedio para proteger al individuo frente a dicha tiranía. Esta obra es bien conocida y también su defensa de lo que hoy llamamos democracia liberal, en la que propone unos límites a la democracia que pocos discuten. Pero Mill también proponía otros, y estos otros los discute casi todo el mundo. Están recogidos en su obra sobre el gobierno representativo.

Dos son, según Mill, los peligros máximos que acechan a un gobierno representativo: la deficiencia en las capacidades intelectuales del cuerpo que controla el gobierno y que esté influido por intereses distintos del interés general, a los que en ocasiones califica de siniestros. El primer problema no 
es, desde luego, exclusivo del gobierno representativo y en especial la monarquía hereditaria puede ser en este sentido mucho peor. Pero hay un tipo de gobierno que es mejor: son las aristocracias de funcionarios, profesionales del gobierno preparados para el mismo, los que la historia muestra que han superado en calidad a los demás. Claro que los gobiernos burocráticos tienen también sus propias enfermedades, en especial la rutina, la falta de creatividad y de "espíritu". Habría que encontrar una manera de evitar los defectos de ambas formas y aprovechar sus virtudes, y Mill propone varios mecanismos institucionales para alcanzar este objetivo.

\section{"EVERYBODY TO COUNT FOR ONE, NOBODY FOR MORE THAN ONE"}

Este famoso dictum aparece en una de las más conocidas obras de Mill, Utilitarismo, atribuido a Bentham ${ }^{9}$. Sean o no palabras literales, recogen bien el espíritu utilitarista del fundador y apuntan al supuesto ético igualitario al que nos referimos antes. Transportado del campo de la ética al de la política, se ha interpretado como una defensa de la regla de la mayoría. La transposición es coherente: dados los supuestos de Bentham, la democracia parece identificarse con la regla de la mayoría. Sin embargo, para Mill esta regla es objetable, y sus argumentos convincentes. La regla de la mayoría puede fácilmente conducir a una tiranía de la mayoría, en la que la voz de la minoría deja de contar. Paradójicamente, la lectura política traicionaría la lectura ética. Mill considera que las opiniones minoritarias tienen que tenerse en cuenta, una proporción acorde a su peso. Para lograr este objetivo, que hoy en día es comúnmente aceptado, Mill propone una serie de medidas para instaurar un sistema proporcional, y en este sentido adopta y adapta las propuestas de Thomas Hare.

Pero si en el sentido mencionado la lectura política del dictum de Bentham peca por defecto, en otro peca, para el gusto de Mill, por exceso. Todas las opiniones, por minoritarias que sean, deben tenerse en cuenta de modo proporcional. Pero, ¿es la opinión de todos igualmente merecedora de ser tenida en cuenta? Al margen de que el gobierno democrático sea el mejor para mejorar las cualidades de los ciudadanos, lo cierto es que en el momento en el que vivía Mill (y probablemente en el que vivimos nosotros) estas son, en efecto, manifiestamente mejorables. Y además son muy distintas entre sí. Mill estaba profundamente convencido de que los individuos estaban dotados de forma muy desigual de las capacidades

9 Aunque es probable que la frase exacta saliera de la boca de Bentham en alguna ocasión, y también que Mill estuviera presente para oírla, lo cierto es que no se ha encontrado entre los escritos del padre del utilitarismo. Los estudiosos afirman que la más parecida aparece en Rationale of Judicial Evidence en términos similares. 
necesarias para realizar juicios políticos. En este hecho encuentra Mill la mejor defensa del gobierno representativo: no es sólo que la democracia directa sea imposible en el seno de los grandes estados, sino que el sistema representativo permite elegir a los mejores para ejercer la soberanía. Permite elegir a una aristocracia.

Sin embargo, aunque este punto le acerca a la defensa tradicional utilitarista de un gobierno representativo, su concepto de la representación le aleja. Un representante es alguien que representa a otro, que actúa, aparece o se presenta en su lugar. Le sustituye. Pero más allá de esta definición común, hay varias formas de entender lo que hace un representante y por tanto varias teorías acerca de la representación política. La primera toma el término en sentido literal: un representante actúa o habla como lo hubiera hecho el representado. Un representante político, en la asamblea de representantes, opina y vota como lo hubieran hecho sus representados de haber estado allí. Así entendida, la democracia participativa conserva la esencia de la democracia directa, solventando únicamente el problema práctico (o la imposibilidad práctica) de reunir a mucha gente. Los representantes son meros delegados. Esta era la versión que los Radicales Demócratas defendían, y que Mill cuestiona. Para él la soberanía representada es soberanía delegada ${ }^{10}$. Los representantes, una vez elegidos, actúan siguiendo su buen juicio y experiencia, teniendo en cuenta los intereses de sus representados pero no, necesariamente, su criterio. Por eso, su mayor preocupación eran las cualidades, intelectuales y morales, de los representantes, cómo asegurar que estos constituyen una auténtica aristocracia, no hereditaria ni basada en la posesión de la riqueza, sino intelectual y moral, una aristocracia de la que pueda decirse que es, realmente, el gobierno de los mejores.

\section{UN HOMBRE, UN VOTO}

Esta popular sentencia representa la traducción política más directa del dictum de Bentham, y se reflejó en el apoyo que los utilitaristas siempre prestaron a la extensión del sufragio, entonces censitario, hasta lo que hoy en día entendemos como una de las bases de la democracia: el sufragio universal. Mill dedica todo un capítulo de su obra sobre el gobierno representativo, el VIII, a defenderlo. Bien es verdad que le pone "peros": hay que exigir unas mínimas condiciones para poder acceder al voto (saber leer y escribir, pagar impuestos etc.). Estas precisiones están a su vez matizadas: los medios para acceder a la educación deben estar al alcance de todos, se

10 Ver, por ejemplo, su artículo en Examiner 4 de julio 1832.

TÉ $\lambda \circ 5$, Vol. XVII/2, 2010 (189-208) 
debe hacer que prácticamente todos, de manera proporcional, paguen impuestos etc., de modo que estas condiciones se extiendan progresivamente hasta que el sufragio alcance a todos. Sin embargo, una de las cuestiones más debatidas, y contestadas, de las propuestas políticas de Mill es lo que se conoce como "voto plural". Para Mill, todos deben poder acceder al voto, pero que los votos de todos tengan el mismo valor es, según sus propias palabras, "un asunto totalmente distinto".

Sin embargo, todos estos matices de Mill tienen un mismo origen. El voto no es un derecho, es un privilegio. Este punto de vista no es en absoluto contradictorio con la afirmación, compartida con sus mayores, de que cada uno es el mejor juez de sus propios intereses. De sus propios intereses sí, y esto hace que se defiendan todas las libertades que se exponen de forma magistral en On Liberty, y que se resumen diciendo que cada uno tiene el derecho de elegir su propia vida y gobernar sus propios asuntos. Pero es que, cuando hablamos del voto en materia política, no estamos hablando de gobernar los propios asuntos, sino de opinar sobre el asunto de los intereses públicos y compartidos, tomar parte en el gobierno de los asuntos de los demás. Y nadie tiene este derecho. Es por tanto un privilegio que hay que ganar mostrando que se tienen cualidades mínimas para gozarlo. Y un vez alcanzado el mínimo, y con él el privilegio, aún nos encontramos con que tales cualidades pueden estar presentes en los individuos en muy diverso grado.

El sufragio universal plantea un problema. Como hemos dicho, el sistema representativo tiene la virtud de permitir que gobiernen los mejores. Pero para que gobiernen los mejores, antes hay que elegirlos, y para esto hay que saber juzgarlos. Por eso la preocupación de Mill se extiende de las cualidades que deben adornar a los representantes a las que deben adornar a los votantes. Porque también entre estos los hay, tanto a nivel intelectual como moral, mejores y peores. Este es el sentido en el que hay que entender las cualificaciones de Mill a la extensión del sufragio. Y hay que entenderlo en su contexto histórico. La extensión del sufragio por la que abogaban los utilitaristas era radical. Ya hemos dicho que entonces era censitario y limitado a los hombres. La propuesta de extender el sufragio a las mujeres y no hacerlo depender de la renta era considerablemente revolucionario. Y, probablemente, origen de no pocas preocupaciones. Hasta la reforma de 1832, el sistema electoral estuvo en manos de la clase terrateniente, que perdió influencia a favor de las élites comerciales. Sin embargo, a finales del XIX en las grandes ciudades la mayoría de la población (más de la mitad en Londres) pertenecía a la clase trabajadora. Después de la reforma, vigente cuando Mill escribió y publico su obra, las restricciones seguían siendo severas, y suponían que en la práctica el $67 \%$ de los adultos 
varones de Inglaterra, Escocia y Gales, y el 80\% de los de Irlanda estaban alejados de las urnas ${ }^{11}$. El voto censitario suponía que sólo un pequeño porcentaje de la población gozaba de participación política, lo que significa que la extensión del sufragio por la que abogaban los utilitaristas suponía de hecho una extensión de una gran magnitud. No es por tanto extraordinario que Mill se preocupara por las cualidades de esa inmensa y nueva masa de votantes. Durante el siglo XIX, las tasas de alfabetización crecieron mucho en Gran Bretaña, sobre todo en comparación con la de otros países, pero aún así se situaban en torno al cincuenta por ciento. Mill era firme partidario de que se remediara tal situación, pero quizá no resulte extraño que, como medida temporal, quisiera dejar fuera del sufragio a una gran parte de la población, literalmente analfabeta.

Sin embargo, todo esto no explica su propuesta del voto plural. Hoy en día, la alfabetización en nuestras sociedades es prácticamente universal (en los mayores de 8 años) y sin embargo sigue siendo cierto que las cualidades intelectuales y morales están desigualmente repartidas. Mill sabe que su propuesta será fuertemente contestada, y que encierra no pocas dificultades prácticas (¿cuantos votos ha de tener en concreto una persona de muchas cualidades? ¿cómo juzgar estas cualidades?) Pero insiste en que "el voto igual no es una cosa buena en sí misma". Y considera que es contraria a la utilidad: "No es útil, sino perjudicial, que la Constitución proclame a la ignorancia y a la ciencia con iguales títulos a gobernar al país" ( Mill 1861, p.111). ¿Cuál es el fundamento de esta controvertida opinión?

Según Skorupski ${ }^{12}$, si hay algo esencial al pensamiento político de Mill (y de otros liberales) es un tipo especial de elitismo al que califica de "liberal". Tal elitismo no se opone al igualitarismo, sino al populismo, entendiendo por tal una doctrina que niega lo que Mill y otros afirman: que los valores intelectuales, morales y espirituales no solo tienen importancia en la deliberación instrumental sino también en la sustantiva, y que tales valores están desigualmente repartidos, lo que hace que algunos individuos sean mejores jueces en estas materias que otros. Estos jueces, según Mill tienen una importancia social vital, y debe permitirse, por el bien general, que ejerzan su influencia.

De acuerdo con muchos estudiosos, este elemento de la teoría política de Mill, tan antipático a ojos de sus contemporáneos como a los nuestros, tiene su explicación en su elitismo moral ${ }^{13}$. Como es bien conocido, su mayor punto de alejamiento con respecto a los padres del utilitarismo está en

11 Sánchez-Beato (2011)

12 Skorupski (1999)

13 Ver por ejemplo Burns (1959)

TÉ $\lambda \circ$ 与, Vol. XVII/2, 2010 (189-208) 
su afirmación de que algunos placeres son intrínsecamente superiores a otros. Y no todo el mundo puede juzgarlos, sino solo aquellos expertos que han podido gozarlos y pueden por tanto saber cuáles son mejores y cuáles peores. Este es un asunto cuya complejidad no puede ser abordada aquí. En lo que resta, nos centraremos en otra visión de la democracia que justifica, desde el utilitarismo, el voto igual.

\section{AÑos DESPUÉS}

Es difícil llevarle la contraria a Mill. No es posible afirmar que todos los hombres son iguales, salvo que uno se refugie en vaguedades como la dignidad humana y el valor moral. Si miramos las cualidades intelectuales y morales concretas de los individuos concretos, no hay más remedio que admitir la desigualdad entre los hombres (y entre las mujeres). Y si afirmamos que estas cualidades son fundamentales para poder opinar en asuntos públicos, y que deben tener mayor peso las opiniones más sabias, no es extravagante concluir que Mill acierta al proponer el voto plural. Para concluir otra cosa, hay que revisar algunos de los supuestos. Y, si somos utilitaristas, hay que revisarlos sin renunciar a los supuestos políticos (y quizá éticos) fundamentales.

Uno de los supuestos más elementales de la política utilitarista es, como hemos dicho repetidamente, que la democracia, si es buena, es buena como medio. Pero ni siquiera los clásicos están de acuerdo a la hora de señalar para qué exactamente resulta ser la democracia un buen medio. Para Bentham y James Mill, es un buen medio (quizá el único) para armonizar los distintos intereses y para que los intereses de todos se tomen en cuenta. Para Mill, es un buen medio para lograr la mejor gestión posible de los asuntos públicos y para mejorar a los individuos.

Mill decía al comienzo de On Liberty que, cuando la democracia deja de ser un ensueño y se lleva a la práctica es cuando salen a la luz sus defectos. Tenía razón. Pero ha pasado más de un siglo desde que lo dijo. Respetando su espíritu, podemos ahora decir que cuando el sufragio universal y la alfabetización general se han hecho realidad, han salido a la luz los defectos del sistema que él proclamaba. Ya en 1942, Schumpeter atacaba lo que calificaba de "mitos de la democracia". Y uno de estos mitos nos importa mucho ahora: los votantes no eligen a sus representantes seleccionando los mejores de entre los posibles. Más bien, se enfrentan a una lista, en el mejor de los casos abierta y muchas veces cerrada, a la que dan o no su voto. Y en la práctica del bipartidismo, la elección se limita a una de dos opciones. Claro que el voto plural no es práctica habitual, y podrían achacarse a esto muchos defectos de nuestras democracias. Pero nuestras democracias representativas han mostrado ser un buen medio para otras cosas. 
Singer ${ }^{14}$ ofrece una defensa de la democracia muy alejada de la de Mill. $\mathrm{Su}$ defensa consiste en alegar que la democracia es el sistema más justo. Lo es porque en él el poder político está repartido de forma igualitaria. Y el reparto igualitario es prima facie justo, a menos que puedan ofrecerse razones muy sólidas que justifiquen un reparto desigual. Mill podría estar de acuerdo, pero alegaría que la desigualdad en las capacidades es una muy buena razón para un reparto no igualitario. La defensa del voto plural, sin embargo, se ve envuelta en una cierta paradoja. De acuerdo, podríamos decir, supongamos (cosa fácil) que hay gente con mejores cualidades para decidir a nivel político, y queremos que ellos nos gobiernen. Para elegirles, hay que tener un buen criterio y, de nuevo, el buen criterio está muy mal repartido. ¿Qué podemos hacer? Hay dos posibilidades. La primera es que admitamos que algunos tienen mejor criterio que nosotros. Podemos creer, por ejemplo, que la opinión de una persona a la que admiramos y en cuyo juicio confiamos debe tener mayor peso que la nuestra. Pero entonces no es necesaria la pluralidad de votos: basta con que preguntemos a esa persona a quién debemos votar (esto no es tan raro. Yo misma lo hago en ocasiones, por ejemplo para votar a un rector de mi universidad: pregunto a quienes conocen mejor a los candidatos y tienen una mejor idea acerca de cómo ha de gobernarse la universidad). Pero puede ser que no haya acuerdo acerca de quién tiene las mejores cualidades, ni acerca de qué cualidades en concreto deben tenerse en cuenta en cada momento. No sólo tenemos distintos intereses, sino también distintas opiniones y juicios sobre todas las cosas. $\mathrm{Y}$ en este caso, cuando la gente difiere sobre quién tiene el mejor criterio, imponer el voto plural significaría privilegiar unas opiniones sobre otras. Podemos (y hasta debemos) debatir el asunto, pero si no hay un acuerdo, o no lo hay en un plazo razonable, tenemos que admitir que el voto igual es la mejor manera, la más pacífica y menos costosa, de decidir la cuestión. Lo mejor es aceptar este compromiso. En palabras de Singer "it would be wise to put aside beliefs about what is perfectly fair, and settle for the sort of compromise represented by "one man, one vote""

\section{Conclusiones}

El razonamiento de Singer nos devuelve en cierto modo a los primeros utilitaristas. La democracia es un buen medio para armonizar intereses y evitar los conflictos. No es un gobierno perfecto, ni garantiza la sabiduría de las decisiones. Pero es la mejor garantía de la convivencia pacífica. Limitada por una amplia protección de los derechos y libertades individuales, tal como proclamaba Mill, es el mejor sistema que los humanos hemos

\section{Singer (1973)}

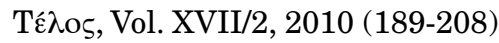


podido arbitrar. Mill era en parte optimista y en parte tendente al perfeccionismo. Y querer perfeccionar a los demás puede no ser una buena idea, si estos no lo admiten de buen grado. Después de todo, la política es el arte de lo posible, y Mill no está lejos de admitir la imposibilidad de implantar su propuesta del voto plural. Es imposible porque la gente no lo admitiría. No consideró que, si lo admitiera, ya no sería necesario.

\section{Bibliografía}

Bentham (1789), An Introduction to the Principles of Morals and Legislation, Clarendon Press, 1879.

Burns (1959), "Utilitarianism and Democracy" The Philosophical Quarterly, Vol. 9, No. 35 (Apr., 1959), pp. 168-17

Burns (1968), "J. S. Mill and Democracy" en Schneewind Mill:A Collection of Critical Essays, Macmillan, London, pp.280-328.

Hume (1987), Ensayos Políticos, Tecnos.

Mill (1959) On Liberty, Longman Library of Primary Sources in Philosophy, 2006.

(1861), Del Gobierno representativo, Tecnos, 1994.

(1863) Utilitarismo, Alianza Editorial, 1984.

Sánchez-Beato (2011) "La representación política durante el siglo XIX en Gran Bretaña”, Política y Sociedad, 2011, Vol. 48 Núm. 1: 117-138.

Schumpeter (1942), Capitalism, Socialism and Democracy,

Singer (1973) Democracy and Disobedience, Clarendon Press

Skorupski (1999), "Liberal Elitism" en Ethical Explorations, Oxford University Press.

Blanca Rodríguez López

Universidad Complutense de Madrid e-mail: blanca.moragon@gmail.com 